\title{
The Role of Artistic Expression in Deciding on a Homeopathic Prescription, with Special Reference to Working with Practicing Artists
}

Ian Ferguson Hamilton *

Founder of the Art and Homeopathy Group, UK

*Corresponding author: lan Ferguson Hamilton, BA Hons, DSH, RSHom, Founder of the Art and Homeopathy Group, UK, Tel: 0777 052 9210; E-mail: ifhamilton@yahoo.co.uk

Rec date: November 13, 2015, Acc date: November 25, 2015, Pub date: December 2, 2015

Copyright: @ 2015 Hamilton IF. This is an open-access article distributed under the terms of the Creative Commons Attribution License, which permits unrestricted use, distribution, and reproduction in any medium, provided the original author and source are credited.

Abstract
Many have noted the connection between art and homeopathy and there is something about the nature of the
creative force and the way in which we perceive the vital force as creative, which puts homeopathy in the same
dynamic place as that which drives artistic inspiration. I have tried to see this connection in a previous article in The
Homeopath looking particularly at case taking.
This paper tries to set the scene about the inclusivity of art and homeopathy by looking at the nature of vitalism
and the breadth of that important quality, expression, as perceived at the outset by Hahnemann, in gaining true
insight of the nature of the suffering of the patient. My work is in the tradition of empirical enquiry, based on
observation and experience and as such accretes more certainty as evidence mounts.

Keywords: Art; Science; Creativity; Dynamic; Vitalism; Archetypes; Vital force; Expression; M.E; Organon; Silica; Pulsatilla; Thuja phosphorus; Oncor Tshaw; Carcinosinum

\section{Case Report}

I would like to begin with a glance at where we came from as vitalists $[1,2]$. Our medicine is based on ancient principles as is the to and fro of humanity. The historian Arnold Toynbee had this to say about the rise and fall of civilisations.

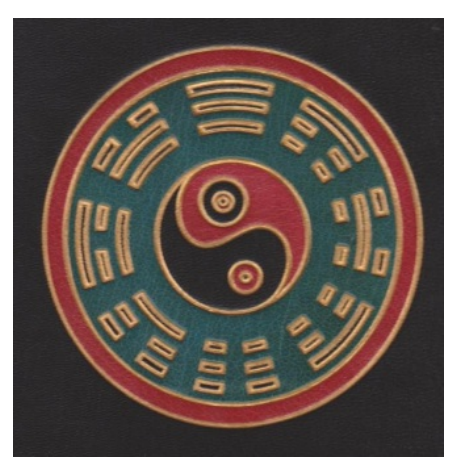

Figure 1: Yin-Yang symbol.

"Of the various symbols in which different observers in different societies have expressed the alternation between a static condition and a dynamic activity in the rhythm of the Universe; Yin and Yang are the most apt; because they convey the measure of the rhythm direct and not through some metaphor derived from psychology or mechanics or mathematics"(Figure 1).

So a dry-as-dust subject like history; can embrace the concept of yin/yang forces as the rhythm of human development. A small leap then for us to say that this is what our sort of medicine has been founded on for centuries and we know it empirically; in the Western and Eastern traditions.

Following the same theme; let us move on to another powerful symbol of our practice - the Caduceus (Figure 2).

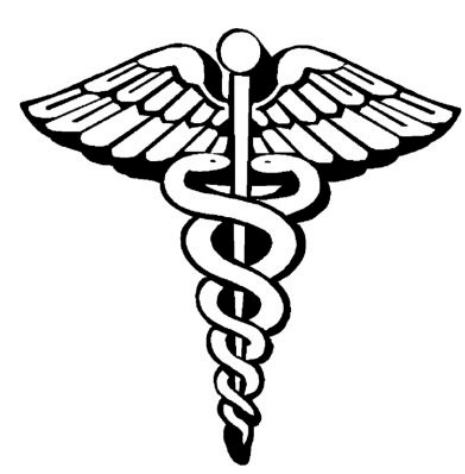

Figure 2: The Caduceus.

This symbol of intertwined staff and serpent was originally the ancient Greek ascription of the staff with wings to the god Hermes; he of the art of communication and of knowledge both occult and scientific. It later became attached; with the serpent; to another god; Asculaepius the god of healing. Not of hygiene but of intervention. So medicine is evoked. But let us look more fully at this symbol and see what its connection is with yin and yang; light and dark; man and woman; good and evil. For the staff is also the tree and the serpent intertwining it is the serpent of the Garden of Eden myth; and this myth is full of meaning of knowledge; of sin; of learning; of male and female and of let's be honest; magic. 
Page 2 of 7

Some authorities say this is also about the male and female principles; with the serpent as the female; goddess principle; prefiguring the idea that the female was the first possessor of power and knowledge. But it's also the Tree of Life which is represented and the outcome of that is self-knowledge. It represents the core of the human condition. When mankind tasted of the fruit; they received the ability to look into and examine the true condition of life; and it proved to be more than they could bear. So we hide behind a fig leaf! (Figure 3).

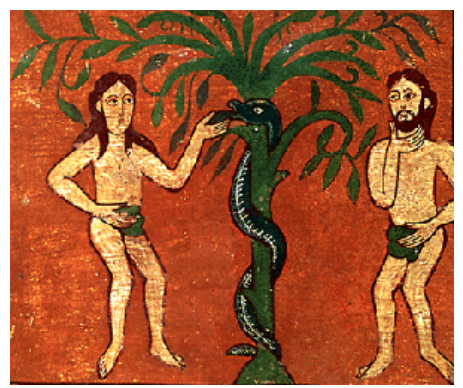

Figure 3: Mankind hiding behind big leaf.

But it also taught us to be observers; to be empiricists and find out those things which would help us in our human frailty. In the staff of the Caduceus; we have the happy flow of life; in the serpent we have self-reflection and knowledge which impedes the flow. The symbol is about how we harmonise these two.

Now we need to look at the principle of vitalism. It is this which imbues all of our work as homeopaths; herbalists; and the other energy medicines. It is the most ancient principle and it encompasses laws of opposites; laws of similars; laws of signatures and generally the notion of empirical knowledge and practice as the basis of efficacy. It is infused with the understanding that there is no division between mind body and spirit when we look at sickness and healing (Figure 4).

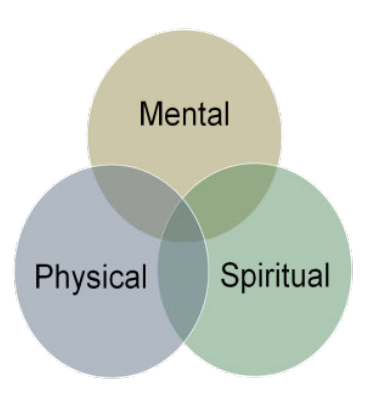

Figure 4: Division between Mind, Body and Spirit.

We need to note that; what is at the centre of the diagram where all elements overlap; is the unquantifiable quality which we can call the vital spirit; force; soul or energy. Various attempts have been made to give it a home in the body; pineal gland is one of the most common; but I prefer to see it as infusing all aspects of the body; without division. Call it the genius. It is diametrically at odds with Cartesian dualism; upon which modern Western allopathic medicine is founded. This has been understood by many empirical scientists; philosophers and poets as well as a genius like Hahnemann and is expressed here by the poet; botanist and scientist J W von Goethe with this:
In the contemplation of nature you must

Regard the One as All;

Nothing is within; nothing is without

Grasp thus without delay

A holy open secret! [3]

It is this dichotomy of thinking which is behind the division between vitalists and so-called rationalists (we are the true rationalists) and which prevents us from having a universal healing philosophy. We as vitalists can embrace the ideas of allopathy without dismay as we can incorporate it into our vision; but it will not work the other way; because to do so would demolish a whole edifice.

Before we move onto the vital force and the case for taking note of expression; a word about our antecedents. We owe much to who has gone before and; just in the Western tradition; we can point to certain historical figures. They are all men but remember that the Eve figure in the myth and the Caduceus; is also the serpent and possessor of knowledge and healing and we have our all embracing female principle.

Hippocrates is the common ancestor. He it was who first suggested it was the spirit (physis) in the organism which healed. The physician assisted that process. Galen later modified this into three spirits; the vital; animal and natural. From here arose the theory of humours of the medieval period. Galen on the whole was a forerunner of the rationalist approach.

Paracelsus is the real forerunner of modern vitalism. He was the first also to promote the notion of the vital force connected with the law of similars. (In plants the essence is similar to the essence of the disease). The vital force (the Archeus) was the intelligent force which balances the organism and protected it from external harm. It also governed the balance of what we eat to preserve health. He located the Archeus in the stomach and gave it the fire principle; in his alchemical understanding; because fire separates the useful from the useless.

Paracelsus gained much of his knowledge and experience from travelling and observing in different parts of the world. He was the first noted deviant from the Galenic tradition and he was vilified by his contemporaries. So he must have had something right! North American Indian medicine men were the bridge between modern herbalism and the vitalist beliefs and practices of our ancestors (Figure 5). For them the whole of the natural world was harmonious and life giving. Their knowledge of herbalogy and the empirical knowledge passed down through the generations was the basis of folk medicine.

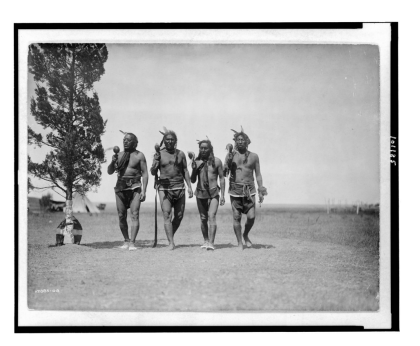

Figure 5: Image of our ancestors.

Our final ancestor is Samuel Hahnmenn who leads us straight into discussing the vital force and how in homeopathy; the intelligence of 
the VF is what leads me directly to my connection between Art and Homeopathy. Hahnemann famously "discovered" homeopathy in 1790; when translating William Cullen's Materia Medica; Hahnemann disagreed with Cullen's thesis that Quinine acted against malaria because it had 5 components (bitters;astringents;aromatics;rubifacient and stomachic tonic) which cured. Instead Hahnemann (who had been experimenting with the single dose for sometime and who believed in the notion of the therapeutic fever) decided that these 5 things together would never produce a fever; and posited the idea that Quinine was a single entity which could produce a fever. He hit on the idea that the fever of Quinine was similar to the fever of malaria. Famously; he took Quinine himself on small doses and produced the symptoms of malaria in himself; which then went away. So was born the first pillar of homeopathy - like cures like. This had been propounded by Paracelsus earlier; but Hahnemann built around it the outward picture of the disease; manifested in the totality of symptoms as a reflection of the inner suffering and which is thrown up by the intelligence of the "spirit like vital force; the dynamis that animates the material organism". Hahnemann says in the Organon that "without the vital force; the material organism is capable of no sensation; no function; no self-preservation" [4]. In other words there is no life and no expression of life and no creativity. The symptoms of disease are in other words; part of a creative force. For me; art and homeopathy.

Before we look at this in detail; for me; the most important homeopathic and vitalist things in how I look at the creative expression of the patient (and of the disease) are these three:

1. Law of similar,

2. The intelligence of the vital force,

3. Doctrine of signatures.

The law of similars takes me to the totality of the picture; the intelligence of the vital force directs me to the most characteristic aspect of the picture and the doctrine of signatures takes me to the creative aspect; typified by the expressions used by the patient - the thing most like them and shown as an image; phrase; dream; gesture; dramatic act or whatever can be seen as a reflection of what remedy the patient needs. This is not the same as the old doctrine of signatures used by herbal medicine long ago; but is my take on that which arises from the conscious and unconscious process of health and disease as a dynamic one.

\section{Why Art and Homeopathy?}

Homeopathy is an art and a science. Hahnemann's Medical Art. When we take a case it's the art of finding the remedy at the root which is the most challenging. If we go back to the Organon; we are told to believe and trust in the expression of the patient as paramount.

"It is certain that; on hearing about a patient's ailments and sensibilities; one has to ascribe belief principally to the patient himself; especially to his own expressions with which he can render an account of his sufferings. However it is just as certain that the investigation of the true and complete image of the disease and its details requires special circumspection; scrupulousness; knowledge of human nature;cautious enquiry and patience - all to a high degree."Organon $\$ 98[5]$

What is this expression? In all of its aspects it's the whole way the patient has their being. Artistic expression is one way of them showing this. Not just drawing a picture; but expressing their creative force. The urge to be creative is human. It's about the inner force beyond survival.
Only when the life force is spent do we lose it. It's the fire which drives the inner creative; expressive self.

With a lot of patients who are artists and in tune with their creative force on a daily basis; they can express themselves and their root in their work; usually as a balance between the conscious and unconscious.

"Man cannot persist long in a conscious state; he must throw himself back into the Unconscious; for his root lives there... take for example a talented musician; composing an important score; consciousnes and unconsciousness will be like warp and weft"J $W$ Goethe [6]

Dualistic separation of body and mind; is not a homeopathic principle. The separation of these; after Descartes; was the beginning of the medical model we know today and is completely at odds with all that we as homeopaths know about the nature of health and cure. If practising medicine in a humanistic non dualistic model is an art; then homeopathy is an art.

On this reading; there can be no reconciliation between homeopathy and modern; so called evidence based medicine; their philosophies are mutually exclusive. There is an acceptance in modern medicine that mind can influence matter in some explanations of how illness can be caused or cured. They are happy to allow placebo as an explanation of homeopathic action; but it is just another dualistic explanation; separating mind and matter.

The real fundamental difference is that homeopathic science is not that of the dualistic medical model. It is a fully realised system; built on an empirical; dialectical understanding of interwoven cause and effect; balance and rebalance; logic and counter logic and Art and Science.

The actions of the remedy are like the process which happens in the creative act. The appearance of disease is much more a creative process from the imbalance of the vital force; than just the external manifestations which allopathic medicine seeks to "cure".

On this basis; it is possible to use artistic expression as a basis for prescribing. What is expressed is a distillation of the root (as Goethe calls it). It can also be called the central delusion; as Rajan Sankaran has done; [7] and see this as what is to be cured. He says; echoing Hahnemann:

"The highest ideal of cure; that is rapid gentle and permanent restoration of health; can only be achieved by the unprejudiced and real awareness of the root of the problem; which is usually a delusion".

\section{Art Matters to Homeopaths}

Art lets us see into and exposes what's inside; outwards. Homeopaths pick up on this in patients. Art can express in a distillation and send messages with it. Curiously; homeopathy is like glass making; nobody knows really what happens here except that when a substance; sand; is heated to a certain temperature it transforms. Homeopathy does this by taking a substance and potentising it; we transform it into another; powerful; energy. It shows the power of the truth. Homeopaths can read this and respond. Art similarly; has the power to bring about change. But it's not just images which do it.

Shall I compare thee to a summer's day? Thou art more lovely and more temperate:Rough winds do shake the darling buds of May; And summer's lease hath all too short a date [8]. 
These words are as moving and as powerful as any image in expressing the fragility of life. Shakespeare has distilled what we all know into four lines. Poetry has this power and as homeopaths we have to do this with what patients reveal to us.

\section{Archetype and Passion}

Many homeopaths in practice have frequently been baffled by the phenomenon of a well chosen big polychrest remedy seeming only partially to reach a curative climax.

Usually this is based on taking and repertorising a case and finding so often that the main polychrests are present. We know that there are thousands of remedies available to us but we prescribe a limited number. There are many possible explanations for this. At this point I wish not to engage with them but instead to offer this idea.

Archetypes of people and remedies have been a focus of how homeopathy can be used for many years. Miasms; Vithoulkas and essences; Vannier and the French school; Bjørndal's Archetypes; Norland's Mappa Mundi. There are other archetypal models which are not just homeopathic: Jung's archetypes; Galenic temperaments (humours); which are the basis of some medical approaches and self improvement and analysis systems. The Platonic archetypes were a guiding principle of aspects of alchemy and of Paracelsus' theories of medicine; amongst other things. Goethe had an important theory of archetypes with his idea of the archetypal phenomenon (Urphänomen) a Platonic model on which he based his way of science - a phenomenology of nature [9].

Many homeopaths and commentators; like Philip Bailey and the late Catherine Coulter; are influential in giving pictures of homeopathic archetypes. Bailey [10]; for example; in his description of Sepia; has 5 sub types to help with a picture of a Sepia woman. These pictures have helped me considerably to understand the remedies; but it is not often that I see a pure picture of the person as remedy. However I often see strong indications for remedies in a person; enough to say; this is a Sepia person or a Sulphur person. I now see that these pictures are valuable and will act at some level on the patient. But the archetype; as I am calling it; is often not the real pathology; the delusion; what is to be cured; but the fixed state of the person. It is a good guide and leads often to a general overall improvement; but the deep cure on all levels is indicated through other signs.

What will really point to the remedy and the delusion and what is to be cured; is the spark; the passion which drives the person. So amongst recent cases; I have seen a man who had a bad post viral reaction and who is a Lycopodium type; respond well to that remedy but still not be cured; until I found that his passion was refurbishing houses and doing the work himself. He called his state "procrastinating" and what he meant was he was marking time in his daily work until he was able to do the work he really wanted. This is his creative spark. He also liked to be the cooperative person and not the leader. He talks a lot about his wife and working with her. He clearly adores her. He was to me in the Ferrum series [11]; at stage 7; still practising. He needed Manganum sulphuricum which he has responded to well. He has now made a decision to quit his job and concentrate on his real passion. He has also made a partnership with a financial backer; so the collaboration element of stage 7 is continuing. He also says that he is less bothered by his physical symptoms; has them in perspective now. I would not have been led to this remedy if I had not focussed on his passion.
So for me; where art and homeopathy come together is in this search for creative expression in the patient. It is not always easily found; or it can be suppressed by the patient. I have one patient who is in the police service. She suffers from bad IBS. Her archetype is very Kali-like and rule bound. Even natural functions have been chemically suppressed (she was on the hormone drenched coil as birth control; but it was to "help" with menstrual problems. So she has had no periods for years). She is also on strong medication for "bi-polar disorder". But her passion is for amateur dramatics. Not in the limelight; but as an organiser behind the scenes. There was good case for Argentum nitricum and the IBS responded well. Also she came off some suppressive drugs; at my request; but some remain; big ones. They went on holiday and the IBS came back. She missed appointment and has not been back. I believe the Kali-like archetype has proved too strong and holds sway. The self who likes to be in theatre is the passion led person and the one who holds the key to cure.

I will always hold the archetypes dear as a guide to a person and a remedy; but experience tells me that only in finding the true expression of the person (but paradoxically; the delusion) the one behind the mask; can we find the cure. In Greek theatre the mask was used by actors to play different roles. The Greek for mask is persona (prosopon) [12]. In my understanding the mask is the archetype; used by the actor to represent a role; but the true self is hidden and has to be revealed in more subtle ways by finding that which is lived from within.

\section{The Cases}

Now I want to go onto cases to illustrate how my thinking and practice has developed.

\section{Case 1}

This was the case which first suggested to me that art was a way into prescribing. It was the case of a young mother - an artist - who was trapped in life with the baby and she loves and cares about the baby strongly at the same time as wanting to escape. I gave her Pulsatilla and Staphysagria; Later; I saw thIs picture on the wall and asked about it. She said it represented freedom. She had painted it. To me the picture was very brooding (Figure 6).

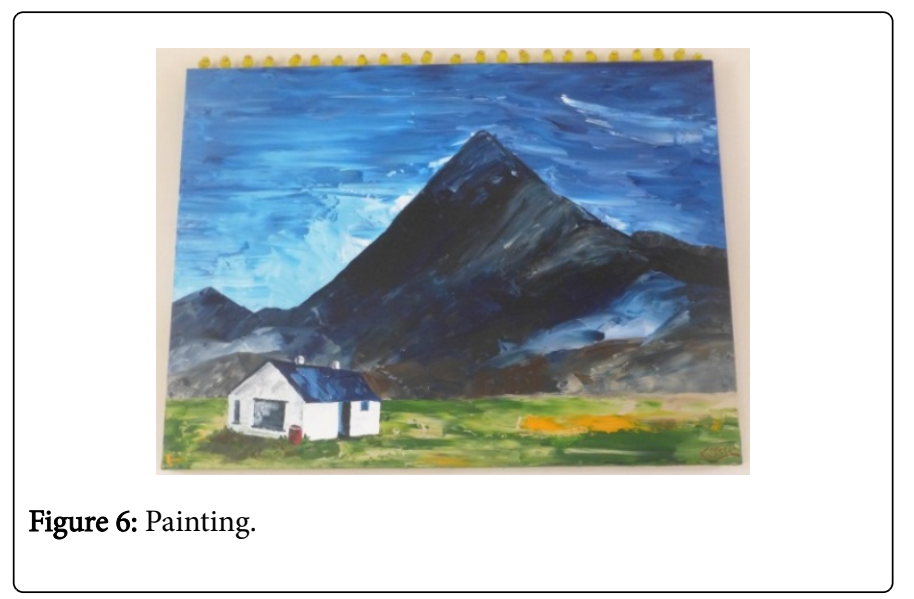

I found it difficult to fit the painting into the case. The only way I could do it was by seeing it as the desire to escape to an earlier life; no matter how dark it is. But then I thought that perhaps the dark brooding mountain may also be her present life; which is weighing 
down on her. There is a dichotomy. It is freedom but it's also what is holding her back. This was much easier to accept now as an image; it made more sense in the case - it can be both things.

We have to be willing and able to interpret art in this way. It's the conscious and the unconscious at work in the same image. It is the creative force.

I ended up giving her Cimicifuga racemosa 200c; on the basis of the desire to escape and travel; the sensitivity to noise during and after pregnancy; the fluttering sensation in the heart region and also as it's in the same family; Ranunculaceae, as Puslatilla and Staphysagria. Here is what Jan Scholten has to say about it [13].

"They fear that when they make a choice for their own good; they will be left alone; so they are in conflict with themselves; not knowing what to choose. The situation they are in is unpleasant; like in a marriage where there is no love anymore. But the idea of leaving the husband produces all kinds of anxieties about how to survive alone in the threatening world; so they often stay in a situation that they do not like at all. There they feel caught; as if bound by wires. Their mood becomes depressed and dark; with the well-known symptom as if a dark cloud surrounds them. This situation can also occur during pregnancy. They feel imprisoned by their child; they cannot divorce".

With my patient; I also feel that this explains the dichotomy of the painting. A dark cloud surrounds her yet she wants to escape to this dark mountain as well.

It seems like a confirmation that the image she painted does represent the conscious and unconscious aspects of her predicament. Her creative; vital force created this image.

The patient responded to the remedy with more of a relaxed feeling. It lasted until the child was once again not sleeping so she became overtired with feeding the child. There is a maintaining cause here. The case continues with the mother now a student of homeopathy.

\section{Case 2}

A woman of 26. A good artist who is not doing her art work; but is waiting around for a fiancé who does not share her passion. But she wants to be a home maker and mother. This is driving her. She developed cystic acne on her face and had many menstrual problems. At first she responded well to Arsenicum; her obvious archetypal remedy; and many anxiety symptoms improved.

When I asked to see her art work; she was clearly obsessed with the life cycle of the salmon (the inland salmon which is trapped in a different land locked cycle) and with the cycles of life and death in the natural world. I debated long with the art and homeopathy group members and eventually made a case for prescribing Oncorhynchus tshawytscha (Salmon). I would like to have given the salmon she was obsessed with but could not obtain it.

Even so; she has responded well; with no sign of the cysts but still with some acne remaining. Her menstrual cycle has settled. When she starts her art work again I know she will be cured. Meanwhile she has an old flat which she lovingly restores.

She has a history of kidney infection; acne and eczema and very bad blind spots or cysts on her chin. The kidney problem started with a urine infection. She was very anxious.
She had a very bad reaction to a BCG injection. She was off school for a long time. Says she developed a stomach ulcer. Had an ME diagnosis at 15 after bad flu.

She is very busy. Holds down 3 jobs which she took to be able to buy a flat. She is a very anxious person. She is recently hot; restless and fidgety; but also likes a hot water bottle for the pain. Lacking confidence in her work.

She worries about being not good enough; of being sick. She has OCD tendencies. Does ritual things; scared of losing control. Generally she is cold but hot with infection. Her hair is different; more greasy and lank. She craves cheese; sweets; averse salt and hates greasy food.

During the case taking she reveals that she trained in fine art. Her passion is stone carving. In particular she loves to do very precise lettering; measured in millimeters. She says she is a perfectionist in this - not perfect; not good enough (Figure 7).

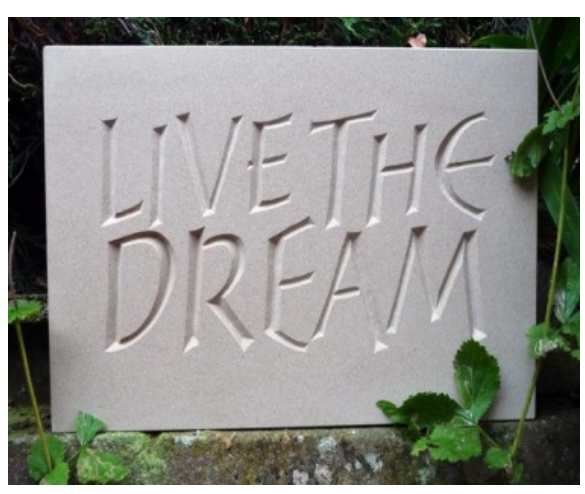

Figure 7: Fine art of stone carving.

I gave her Arsenicum 200c; her archetypal remedy. it was only when she told me about her art that I saw her perfectionism. I see that she is in the Cancer miasm; so an archetype at work here as well.

These are some of the images she sent. Also I had these descriptions.

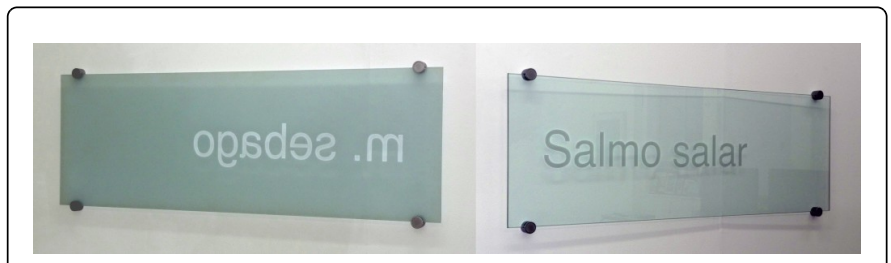

Figure 8: Land locked Salmon.

\section{Land Locked Salmon}

"Two panels of sandblasted glass cut to the actual size the female of the species grows to. The text dissipates from the centre in both directions. Reading from left to right; 'Salmo salar' is Latin for the Atlantic species of salmon. Meanwhile; read in the opposite direction; 'm. sebago' refers to the land-locked salmon which has evolved from the Atlantic species. The ' $m$. sebago' panel has been sandblasted on the underside so the text appears trapped beneath the surface; reflecting the fish caught in the bodies of water when the glaciers melted and sea levels rose; leaving them trapped and cut-off from the sea" (Figure 8). 
Citation: Hamilton IF (2015) The Role of Artistic Expression in Deciding on a Homeopathic Prescription, with Special Reference to Working with Practicing Artists. Altern Integr Med 4: 205. doi:10.4172/2327-5162.1000205

Page 6 of 7

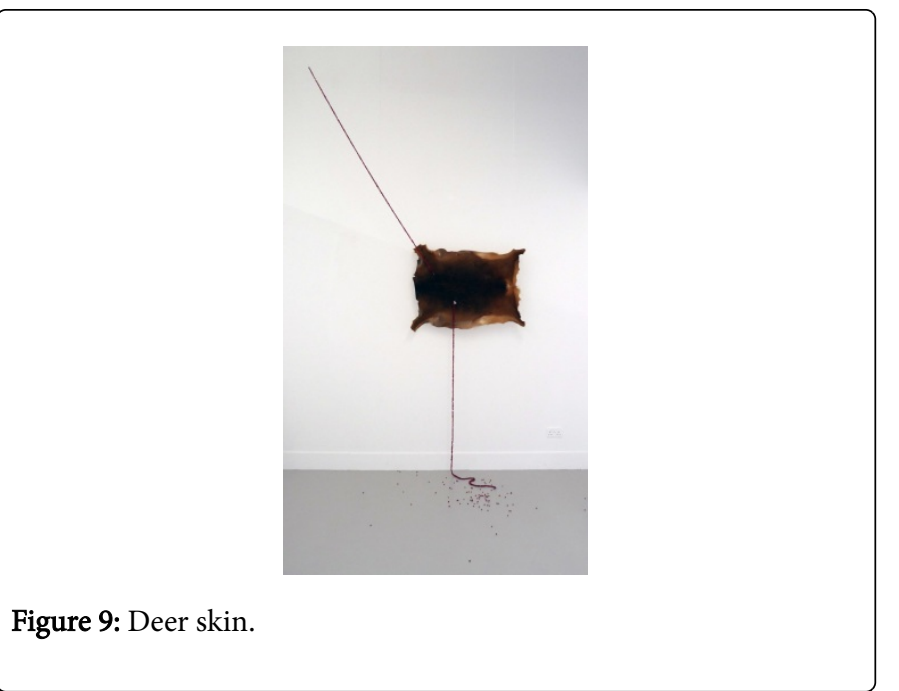

\section{Deer Skin and Rowan}

"What befalls the earth befalls all the sons of the earth. This we know: the earth does not belong to man; man belongs to the earth. All things are connected like the blood that unites us all. Man does not weave this web of life. He is merely a strand of it. Whatever he does to the web; he does to himself".

Chief Seattle (1786-1866)Rowan berries emerge in the gallery as if from nowhere and penetrate the deer hide through the entrance and exit holes left by a bullet. The straight angular line of berries entering the hide creates tension; reflecting the anticipation before the kill. During its life the Rowan berries (a symbol of protection) fed the deer; now after its death they fertilise the soil for new growth (Figure 9). [14]

This is from the overview of the proving of Salmon by Jeremy Sherr

"Sudden deep conviction that I would find my soul mate or life partner. Remembering how I have always been with the wrong man... I feel as if everyone is finding their partner or having babies. I'm obsessed with family and children. I want a baby and a family; a house; a dog; even a husband. I want to have children and be with children; now immediately!... very intense fear of not being able to have children. I want to get engaged and married... strong desire for a home and a relationship. Not feeling at home in my original home. Huge sadness of something missing - of not knowing where my home is").

\section{Follow up 8 October 2015}

- Sleeping much better

- More alert and refreshed

- More assertive

- Now < after menses 34 day cycle

- More relaxed

- She says she must get things sorted out with G (fiancé)

- Went out for dinner last night with friend she invited.

- Skin a lot better on hands and face (I can see this is so - much better; no cysts)

- Feels more open. Doing creative thinking. Been invited to do an album cover for a friend; a boy she gets on with and who writes music.
- "sometimes I forget I'm an artist"

- OCD is better. "Less self centred" The embarrassment is less. Still won't confront people she's afraid of.

- People at the volunteer work her type of people. "She's on their spiritual wavelength. It's not just politics".

- Menses a complete change to < after from previous pattern of < before. No PMS really. Bladder better.

- Eating better and has put on weight. (I can see that in her face. She looks a lot prettier)

\section{Rx Salmon 200c}

To conclude this case study; I would argue that this is exhibiting the idea that the remedy; the homeopath; the patient (and in this case; the artist) are working in a conscious/unconscious way in arriving at the cure. Earlier; I said that when this patient starts to do her art work again; she will be on the way to cure. The tensions which she has are her Salmon-like determination to find her mate and have children; but also in fighting against his family who seem determined to exclude her. Allied to this is her language; in the last follow up; about being on the same spiritual wavelength as the people she is working with; which is a profound statement; and her recognition that "sometimes she forgets she's an artist". This is the conscious/unconscious at work.

\section{The Future}

The art and homeopathy project is new but draws on so much history; experience and practice; together with a sound base from Hanemannian homeopathy. In many ways people say that they wonder why this has not come together before. In a sense it has. There is a recognition that so much has gone before and that this is a restatement of what is already understood.

Nevertheless; the initiative has attracted a lot of people who want it to progress and so there needs to be a planned future. We have been asked to contribute regularly to Homeopathic Links; the International Journal for Classical Homeopathy; by the editor in chief Harry van der Zee. "Since its establishment in 1987; Homoeopathic Links has become an important and respected publication in the world of alternative medicine. Today it connects homeopaths in more than 50 countries and promotes exchange between the different directions and philosophies of homeopathy and naturopathy" [15].

This is recognition that the initiative has important implications for attracting views and contributions to a fairly universally understood idea. As a group; we are making our own plans; but the nature of the project is such that we will respond to developments as required. It is important for us a varied and widely spread group that we meet regularly to share ideas and experience; so the points here are for our group to work with flexibly.

Anyone else wanted to be involved is welcome; whether from homeopathy or another branch of alternative medicine.

\section{References}

1. Hamilton Ian, Art and Homeopathy, a way of case taking. The Homeopath, Autumn 2014.

2. Wood M (2000) Vitalism The History of Herbalism, Homeopathy and Flower Essences, North Atlantic Books USA.

3. Goethe JW (1818) Epirrhema.

4. Hahnemann S, Organon of the Medical Art (6thedn) Ed. O'Reilly 0031996 , Birdcage Books USA. 
Citation: Hamilton IF (2015) The Role of Artistic Expression in Deciding on a Homeopathic Prescription, with Special Reference to Working with Practicing Artists. Altern Integr Med 4: 205. doi:10.4172/2327-5162.1000205

Page 7 of 7

5. Ibid Hahnemann S.

6. Goethe JW, quoted in Whyte LL (1962) The Unconscious before Freud Anchor Books pp. 119-120.

7. Sankaran R (1994) The Substance of Homeopathy Homeopathic Medical Publishers Mumbai.

8. Shakespeare W, Sonnet 18, http://www.poetryfoundation.org/poem/ 174354 .

9. Seamon D, Zajonc A (1998) Goethe's Way of Science: A Phenomenology of Nature, Albany, NY: State University of New York Press.
10. Bailey,P M (1995) Homeopathic Psychology, North Atlantic Books.

11. Scholten J (1996) Homeopathy and the elements Stichting Alonissos, Nederland.

12. https://en.wikipedia.org/wiki/Persona.

13. http://www.qjure.com/remedy/actaea-racemosa.

14. Sherr J (2002) Dynamic Provings Vol II Dynamis Books.

15. http://www.thieme.com/books-main/complementary-medicine/product/ 2173-homoeopathiclinks. 